Fecha de recepción: junio 2013 Fecha de aceptación: marzo 2014 Versión final: mayo 2015

\section{El Ángel Blanco. Desde Heraldo de la Resurrección hasta Portador de Fortuna. Comercialización del Arte Religioso en la Serbia post-comunista 1}

Aleksandra Pavićević *

Resumen: Los murales en los templos cristianos ortodoxos siempre han tenido el siguiente objetivo: visualizar el orden litúrgico y completar la experiencia religiosa del tiempo y espacio sagrados. Fuera de los templos y oficios religiosos, los creyentes podían mantener el contacto con estas historias santificadas y sus santos, a través del uso de los iconos que han sido una parte inseparable de la vida cristiana siempre después del período de la iconoclasia. En la época comunista, los grandes éxitos del arte del cristianismo ortodoxo se observaban fuera del contexto religioso estricto. El cambio de actitud hacia las artes visuales influyó en su comercialización que, en gran medida, descuidó los dogmas originarios en los que este tipo de arte estaba basado. Un hecho interesante es que la propia Iglesia Ortodoxa Serbia contribuyó de manera importante a este proceso comercializando productos de arte ortodoxo.

Este trabajo se centrará entorno a un caso específico -el caso del Ángel Blanco- un fresco mundialmente famoso, del monasterio Mileševa (sudoeste de Serbia). En las últimas décadas esta composición ha pasado por serias "reinterpretaciones" en las que su tema principal -mostrar la tumba de Cristo vacía después de Su resurrección- ha sido marginalizado por haber destacado la figura del ángel blanco, a través de la reproducción sólo de una parte de la composición.

Este caso presenta un testimonio de varios niveles de los actuales procesos sociales y culturales en Serbia: da testimonio acerca de un largo proceso transicional que frecuentemente suponía invenciones y falsificaciones de las tradiciones nacionales y religiosas, testifica, asimismo, sobre las formas especiales de la llamada nueva religiosidad, que es considerado a la vez tanto un fenómeno local como global, y por último, pero no menos importante, testifica sobre la secularización de las prácticas y fe ortodoxas.

Palabras clave: ángel blanco - comercialización - ícono (cristiano) ortodoxo - resurrección - secularización.

[Resúmenes en inglés y portugués en la página 336]

${ }^{(*)}$ Licenciada en la Universidad de Belgrado, en el departamento de Etnología y Antropología. En el mismo departamento realizó el Máster cuya Tesis fue "Matrimonio popular y eclesiástico en la sociedad rural serbia" y el Doctorado cuya tesis fue "Vida matrimonial y familiar en el norte de Šumadija en la segunda mitad del siglo XX”. Actualmente trabaja como investigador superior asociado y es presidenta del Consejo Científico del Instituto Etnográfico de la ASCA. 
El papel y el significado de los íconos en la tradición ortodoxa es un hecho muy conocido y elaborado por muchos teólogos e historiadores del arte. Debido al hecho de que en un icono están unidas las características complejas del símbolo y la narración directa, el mismo ha obtenido el estatus de un portal específico, un pasillo entre la esfera terrenal y celestial, convirtiéndose así en una parte inseparable del oficio religioso desde la historia temprana del Cristianismo (Uspenski, 2000: 113).

Tanta importancia del ícono probablemente se podría explicar a través de la enseñanza cristiana sobre Jesús Cristo como creador del primer ícono, llamado 'icono hecho sin manos', y también a través del hecho de que desde los primeros siglos del Cristianismo en las paredes de las catacumbas se pintaban las escenas del Antiguo y Nuevo Testamento (EŽR, 1992: debajo del Icono). A lo largo del tiempo esta expresión visual de la primera fe cristiana se ha convertido en un tipo de designación de los templos cristianos en los que todas las intervenciones artísticas, al igual que los oficios religiosos, han sido dirigidas hacia el misterio central de la vida cristiana.

También es un hecho bien conocido que a lo largo de la historia del Cristianismo existían antagonismos acerca de adoración de íconos. El conflicto más severo de este tipo fue la crisis iconoclasta en el siglo VIII. Los oponentes de aquel tiempo consideraban esta actitud hacia el icono como una clase de idolatría, lo que recordaba al culto pagano a los dioses. Este conflicto se resolvió en el Concilio de Nicea (787), donde el papel y el significado del icono en el oficio religioso cristiano fueron determinados con precisión. Se estableció la distinción entre adoración -se consideraba que pertenecía a los iconos-, y culto que se relacionaba exclusivamente con el propio Creador y Salvador (Milaš 1, 2004:18,611).

Para difundir el Cristianismo entre los serbios, los gobernantes serbios medievales estaban entre otras cosas, construyendo iglesias. Varias de ellas se han preservado hasta la actualidad con los frescos en sus paredes. Algunas de estas pinturas son consideradas las muestras más hermosas del arte ortodoxo oriental. Además, los gobernantes serbios y sus familias a menudo tenían en su posesión iconos famosos que se usaban no sólo para la oración, sino también en los rituales estatales y políticos, así como en las guerras (Pavićević, 2010).2 Los datos sobre la presencia de los iconos en la vida cotidiana de la gente común de aquel tiempo son pocos e indirectos. Podemos suponer que los altares caseros existían sólo en los círculos aristocráticos. Por otra parte, numerosas tradiciones y rituales folclóricos relacionados con ciertos frescos en ciertas iglesias, posiblemente nos llevarían a la conclusión de que los mismos tenían un papel importante en la vida religiosa de las comunidades locales que vivían cerca de estos monasterios e iglesias. Esta relación era una mezcla de las nociones paganas y cristianas y a menudo se basaba en las supersticiones y rituales mágicos que rodeaban determinada imagen. ${ }^{3}$

Después de la caída de Serbia bajo el Imperio otomano, a finales del siglo XIV, la Iglesia Ortodoxa Serbia se convirtió en el único bastión de la identidad nacional serbia y en la conservadora de las memorias de 'la edad de oro' de la independencia serbia y la sinfonía de la iglesia y el estado, lo que caracterizó la Edad Media. La historia escrita bajo el auspicio de la Iglesia Ortodoxa Serbia se basó en gran medida en el legado espiritual dejado por gobernantes serbios medievales y sus familias (cristianización, autonomía de la Iglesia, construcción de los monasterios e iglesias...). El testimonio de la gran importancia que estas tradiciones tuvieron para la gente serbia está contenido en el hecho de que las igle- 
sias, los frescos y las reliquias sagradas a menudo eran metas de las acciones destructivas realizadas por los soldados islámicos. ${ }^{4}$ Sin embargo, los riesgos de confesar la fe cristiana en tiempos en que se estaba bajo regencia musulmana, al igual que un estado lamentable dentro de la Iglesia Ortodoxa Serbia, contribuyeron al desarrollo de un tipo específico de fe popular, que se basaba mucho más en un cristianismo tradicional y folclorizado que en sus dogmas oficiales.

La Edad Moderna, es decir el siglo XIX, trajo consigo la liberación nacional y la creación de un nuevo y moderno Estado serbio. Los paradigmas ideológicos del nuevo estado se basaban en las ideas del romanticismo nacional, racionalismo europeo e iluminación. A nivel del modelo político esto implicaba la creación del estado secular y su separación de la iglesia (Timotijević, 2001:39). A nivel colectivo -la identidad estatal y social, la fe cristiana- seguía siendo el emblema, designación de la pertenencia y la identificación, pero al tratarse de las prácticas religiosas concretas, el espíritu de la época se podía considerar como la fuente de una nueva actitud hacia la fe y la religión, que implicaba la secularización gradual. La herencia de la época parecía ser un terreno productivo para la ideología comunista que en Serbia y Yugoslavia se convirtió en la ideología dominante después de la Segunda Guerra Mundial.

Es conocido que el modelo del comunismo en Yugoslavia fue moderado. Esto se puede notar, entre otras cosas, en el hecho de que no hubo tantas persecuciones de la religión e iglesia como en otros países de Europa del Este. Además, la movilidad social vertical a menudo dependía de la pertenencia al Partido Comunista y del respeto de los modelos de comportamiento deseables. Más tarde suponía el desprecio hacia la iglesia y la religión y difusión activa de valores de una sociedad nueva, comunista, 'no alienada'. Este ambiente ideológico y la previa herencia cultural eran las razones por las que se redujo, de manera intensiva, el número de participantes regulares en la vida de la iglesia. Durante las décadas siguientes los templos se mantuvieron casi vacíos, el número de rituales eclesiásticos se redujo radicalmente y la fe se convirtió en un asunto de elección individual y una práctica privada, familiar, y a veces secreta (Jovančević, 2000: 274). ${ }^{5}$

Como se ha mencionado antes, la estrategia política de la dirección estatal no suponía una confrontación directa y abierta con la iglesia, sino un adoctrinamiento intensivo y unas medidas específicas de política cultural. Esto implicaba abolición de la educación religiosa e introducción del marxismo en las escuelas, revisión del calendario de las festividades cristianas, es decir su sustitución por nuevas fiestas socialistas, y una actitud especifica hacia la herencia histórica que se relacionaba principalmente con la identidad cristiana de la nación. Lo último resulta particularmente importante para el tema de este trabajo. Lo que ocurrió fue que se renombraron y calificaron de nuevo los testimonios más importantes de la gloria del antiguo Estado cristiano. Concretamente, durante los años 50 del siglo XX se fundaron los Institutos repúblicano y federal para la Protección de Monumentos, cuyo objetivo principal fue la conservación de los monumentos históricos, entre los cuales las iglesias y los monasterios fueron los más importantes.

Los proyectos de preservación suponían la conservación y restauración basada en los documentos disponibles. El mayor número de los monasterios e iglesias medievales fue declarado 'categoría cero de monumentos', lo que significaba que se tenían que conservar en la manera en que se encontraban. Cualquier intervención sin el permiso del Instituto 
estaba prohibida. El proyecto duró varias décadas durante las cuales los oficios religiosos fueron inhabilitados. De templos dedicados a la oración, pasaron a convertirse en museos de los frescos descoloridos y destruidos, testimonios de los tiempos pasados a los cuales, de acuerdo con la nueva ideología del Estado, pertenecía la religión (Radić, 2002).

Una de las iglesias que compartió este destino fue la iglesia del monasterio Mileševa con el fresco del Ángel Blanco, cuyo destino es el tema principal de este trabajo.

El Ángel Blanco es parte de una composición más grande, Las Miróforas en la sepultura de Cristo, pintada en la técnica del fresco en la nave central en la pared del sur del pasillo occidental perteneciente a la iglesia principal del monasterio de Mileševa, en el siglo XIII (Radojčić, 1963:78). Siguiendo las reglas iconográficas, el pintor ilustró el evento del Nuevo Testamento: la llegada de las Miróforas (las portadoras de mirra) a la sepultura de Cristo la mañana del domingo, después de Su Crucifixión y funeral, con el fin de tratar Su cuerpo con la mirra. Pero al llegar, allí encuentran la entrada al sepulcro destruida, y en vez de 'el cuerpo del difunto', ellas ven sólo vendas del funeral y a un ángel en un vestido blanco quien anuncia la noticia jubilosa sobre la Resurrección de Cristo (Mat. 28, 1-7; John. 20, 11-18). De acuerdo con esto, en la composición de Mileševa uno puede ver a dos mujeres -portadoras de mirra-, al Ángel Blanco que está sentado, o bien, en lo que se refiere a sus alas desplegadas, flota sobre la sepultura abierta enseñando las vendas del funeral en ella. Él lleva una vara en la mano derecha. Hay una cinta decorativa en el vestido, encima de su hombro izquierdo, que según algunas interpretaciones es el símbolo de su rango. En el fondo de la pintura se pueden apreciar los 'soldados dormidos', que se durmieron mientras cuidaban la sepultura de Cristo, para evitar que los apóstoles robaran su cuerpo e hicieran que su fama póstuma fuera más grande que la que mereció durante su vida terrenal (Mat.27,63-66) [Ver Figura 1 en Catálogo de Figuras en página 332].

Según la tradición cristiana ortodoxa acerca de las fuerzas inmateriales, el Ángel Blanco no es un tipo particular del ser angelical. Según el papel que él tiene en este fresco, lo más probable es que él sea el Arcángel Gabriel, quien muy a menudo aparece como heraldo de los misterios de Dios. Como una vez anunció la concepción milagrosa de Dios, aquí anuncia la Resurrección de Cristo (Jovanović, 2004: 17). El vestido blanco que lleva en este ícono no representa su ropa 'habitual' sino el higo que simboliza la alegría y la felicidad de la Resurrección. En otras composiciones (por ejemplo: Asamblea de los Arcángeles o la Anunciación), el Arcángel Gabriel se encuentra representado de una manera completamente diferente -en un vestido de color, con claras señales de su rango angelical- que lo diferencia de otras fuerzas inmateriales de esta jerarquía celestial (Kajmaković, 1977: 296) [Ver Figura 2 en Catálogo de Figuras en página 332].

A pesar de los acontecimientos históricos tempestuosos, las Miróforas testificaron en paz sobre el misterio central de la fe cristiana -la Resurrección- hasta el siglo XVII cuando, a causa de los daños, las pinturas antiguas fueron cubiertas por una nueva capa de frescos (Radojičić, 1963: 51,52). Aunque, en los marcos artísticos, valían mucho menos que las pinturas del siglo XIII, las nuevas pinturas tuvieron un papel significante en la protección de las composiciones antiguas de las destrucciones intencionales y del deterioro.

Las nuevas capas de las pinturas de Mileševa fueron destruidas por un incendio, después del cual las obras maestras antiguas reaparecieron (Todić, 1992). Durante los años 80 del siglo XIX el arqueólogo británico sir Arthur Evans, después de su viaje por Serbia, pu- 
blicó un artículo en Manchester Guardian. En el mismo escribió que "nada de lo que creó Giotto supera la belleza del Ángel del legado real serbio, en el monasterio Mileševa” (Đurić, 1987: 27).

El hecho de que Sir Evans no se ocupara de los contenidos dogmáticos de la pintura, sino exclusivamente de sus valores artísticos por lo que introdujo sólo este tipo de detalles, no sorprende. Pero el acto de que se hayan hecho otras reproducciones de este detalle extraído que hasta la actualidad ha suprimido casi por completo el resto de la composición exige que la responsabilidad de los actores principales de este proceso sea reconsiderada.

Situar en un tiempo preciso el inicio de la reproducción masiva de los iconos y otras pinturas religiosas resulta una tarea bastante difícil. En el año 1947 el Consejo de Ciencia y Cultura de la República Federativa de Yugoslavia, con la ayuda y educación por parte de los copistas profesionales de Francia, empezó el proyecto de la producción de copias de los frescos serbios medievales. El objetivo de este proyecto fue fundar un archivo especial que debía preservar los bellos originales obsoletos. Durante los años siguientes la acción fue apoyada por el Consejo de organización de la exposición del arte medieval, que tuvo lugar en París en 1950. En el Palacio de Chaillot en la capital francesa, 160 copias de frescos y 105 copias de esculturas estuvieron expuestas. Las Miróforas en la sepultura de Cristo del monasterio Mileševa estuvo entre ellas. Es posible que un gran aprecio de los críticos extranjeros impulsara la comercialización de las piezas artísticas medievales, pero es interesante mencionar que la iglesia ortodoxa serbia aparece como uno de los participantes principales de este proyecto. Decir que la razón de la reproducción masiva de íconos fue exclusivamente de naturaleza económica, sería un poco injusto. Incluso podemos estar seguros de que en tiempos de ateísmo e intensiva secularización de la sociedad yugoslava la reproducción se llevaba a cabo con fines misioneros en primer lugar. Pero también podemos estar seguros de que la inserción del Ángel Blanco y la reproducción masiva del ícono Ángel Blanco no tuvieron solamente antecedentes comerciales, sino principalmente ideológicos.

Debido a la reproducción masiva, en diferentes materiales y en diferentes ambientes, siempre reconocible y fácilmente 'legible', el Ángel Blanco se convirtió en un producto por excelencia de la cultura kitsch. El Arcángel Gabriel fue degradado del heraldo de la Resurrección al construido ángel blanco de la angelología ortodoxa, al símbolo artificial de la fe nacional cuyo dogma central -el dogma sobre la Resurrección- fue borrado de los recuerdos sobre 'ángeles-peregrinos', junto con el corte de algunas partes de la composición Las Miróforas en la sepultura de Cristo [Ver Figura 3 en Catálogo de Figuras en página 333]. La ideología comunista y las peculiaridades de la religión popular serbia eran una base excelente para este proceso. La oportunidad de un 'examen recuperatorio' que surgió durante los años 90 del siglo XX con el renacimiento de la religión, no fue aprovechada ni por parte de la Iglesia Ortodoxa Serbia ni por otras instituciones nacionales. La producción masiva del icono Ángel Blanco continuó, así, hoy en día puede verse en diferentes lugares: en casas, iglesias, escuelas, oficinas, casas de juego, también en las tarjetas de crédito y telefónicas, en las botellas de cerveza, toallas, íconos 'profesionalmente pintados' y en las tiendas eclesiásticas, al igual que en muchos otros lugares donde la asociación de 'la protección celestial' puede inspirar a la gente a que gaste el dinero y/o la misma asociación puede sacar ganancias. La Iglesia reaccionó contra estos abusos, pero no por la falsificación del contenido o por el significado de la composición, sino por los marcos profanos en los que fue expuesto 
el Ángel Blanco (Mirjana Petak, en www.politika.co.yu/ilustro/2401/2). El Ministerio de Cultura de la República Serbia respondió a este llamado de atención y prohibió el uso del ícono Ángel Blanco en las tarjetas de crédito nacionales (Insajder, el 17 de octubre, 2004) [Ver Figura 4 en Catálogo de Figuras en página 333].

Pero el proceso ha ido muy lejos.

Hoy en día, las reproducciones del Ángel Blanco aparecen en dos versiones: en la primera uno puede ver sólo al Ángel que está sentado en un cubo de mármol y está tocando 'algo'. Ese algo, que en realidad es la sepultura de Cristo, al igual que las Miróforas, se queda fuera de esta imagen. En la segunda versión está el Ángel y la sepultura, pero otra vez sin las Miróforas. Independientemente de la versión que tiene en sus oficinas o en sus espacios privados, la gente, rara vez sabe qué está representado exactamente en el ícono: ¿Dónde está sentado el Ángel Blanco y qué está haciendo?6 Lo que resulta especialmente interesante es el hecho de que en algunas tiendas eclesiásticas uno no puede comprar el ícono Las Miróforas en la sepultura de Cristo, hasta que no recuerde al vendedor sobre la existencia del Ángel Blanco en el ícono [Ver Figura 5 en Catálogo de Figuras en página 3xx].

Como ya hemos mencionado, los años 90 del siglo XX trajeron consigo el renacimiento religioso a la sociedad serbia. La superficialidad como una característica importante de este proceso, que frecuentemente suponía invención de nuevas tradiciones, fue una base sólida para el florecimiento no sólo de aspiraciones religiosas institucionales, sino también de diferentes cultos, prácticas místicas, sectas ocultistas y también de supersticiones. Una discontinuidad con el pasado, escasa educación dogmática y falta de eficiencia de los misioneros de la Iglesia Ortodoxa Serbia crearon un terreno fértil para el desarrollo de este tipo de nueva 'espiritualidad'. En un contexto histórico, cultural y antropológico como ese, el Ángel Blanco se convirtió en San Ángel Blanco, un ícono completo de la época cuya veneración recuerda a la tradición, al pasado, al patriotismo, a la protección de Dios, pero no a la Resurrección. La conciencia sobre el acontecimiento central de la fe cristiana fue sustituida por unas ideas anticuadas sobre un protector con características mitológicas y demonológicas, un portador de buena suerte, el que cuida de accidentes y enfermedades y santo patrono de las transacciones económicas.

No obstante, 'la tradición' de la veneración del Ángel Blanco es la realidad de una parte de la sociedad serbia contemporánea. Como tal da testimonio sobre ciertas necesidades de sus consumidores al igual que sobre las maneras en las que satisfacen su vocación. Por otra parte, considerando el proceso a lo largo del cual se había creado esta tradición, éste abre la puerta a una nueva relativización y manipulación de los contenidos de la tradición cristiana o tradición en general. 


\section{Notas}

1. Este trabajo es parte del proyecto 177028, financiado por el Ministerio de Educación y Ciencia, República de Serbia.

2. Cabe mencionar que la costumbre de usar íconos con estos fines fue muy difundida tanto en el Cristianismo oriental como en el occidental sin diferenciación. Las imágenes sagradas se podían ver en las imágenes guerreras y al frente de las procesiones por medio de las cuales se inauguraron ciertos gobernantes. Así, el duque bávaro Maximiliano Emanuel II llevó consigo el ícono de la Virgen María cuando conquistó Smederevo, una ciudad en Serbia central, en 1688. (Tatić, 2007: 569,534; Timotijević, 2000:222.)

3. Esto significa que se creía que si uno lograra tocar el icono o mondar su color o dormir cerca de la pared pintada, eso podría llevar al cumplimiento de diferentes deseos.

4. Uno de los acontecimientos cruciales fue la quema de las reliquias de San Sava, uno de los santos nacionales más importantes y fundador de la Iglesia Ortodoxa Serbia. Esto ocurrió en el año 1594 en Vračar (que era entonces una pequeña colina cerca de Belgrado).

5. Aquí nos referimos, en primer lugar, al bautismo y a la boda, mientras que los rituales funerarios quedaron bajo las alas de la iglesia.

6. Una encuesta realizada en la Escuela secundaria de artes y oficios de Belgrado y entre los intelectuales de alto nivel de formación mostró un bajo índice de aquellos que estaban informados sobre algunas cuestiones básicas acerca de esta pintura: acerca de dónde se situa, cuál es su contenido y significado (para más información véase: Pavićević, 2005).

\section{Bibliografía}

Đurić, V. (1987). Mileševsko najstarije slikarstvo. Izvori i paralele. (Las pinturas más antiguas de Mileševa. Fuentes y Paralelas.). In: Mileševa en la historia de la gente serbia. Academia Serbia de Ciencias y Artes. Belgrado, p. 27-36.

EŽR (1992). Enciklopedija živih religija. (Enciclopedia de las religiones vivas). Belgrado. Jovančević, N. (2000). Šematizam šumadijske eparhije (El esquematismo de la eparquía de Šumadija). Kragujevac.

Jovanović, B. (2004). O Anđelima. (Sobre los Ángeles). Belgrado.

Kajmaković, Z. (1977). Georgije Mitrofanović. Sarajevo.

Insajder, el 17 de octubre, 2004.

Milaš, N. (1895/2004). Pravila pravoslavne crkve sa tumačenjima. (Las reglas de la Iglesia

Ortdoxa con explicaciones). Novi Sad,Belgrado, Šibenik.

Pavićević, A. (2010). Putujući kroz vreme. Poštovanje i upotreba Bogorodičinih ikona u srpskoj tradiciji i danas. (Viajando por el tiempo. El respeto y el uso de los iconos de la Virgen María en la tradición serbia y hoy en día). Zbornik Matice srpske za društvene nauke,no. 133. Novi Sad,p. 75-85. ISSN 0352-5732

(2005). Шта ради и где седи Бели Анђео? (¿Qué está haciendo y dónde está sentado el Ángel Blanco?). Glasnik Etnografskog instituta SANU, p. 187-194. ISSN 0350-0861. 
Petak, M. (s/f). Čuvar anđela čuvara, Ilustrovana politika. Disponible en: www.politika.co. $\mathrm{yu} / \mathrm{ilustro} / 2401 / 2$.

Radić, R. (2002). Država i verske zajednice 1945-1970. (El estado y las comunidades religiosas 1945-1970). Belgrado.

Radojčić, S. (1963). Mileševa. Umetnički spomenici Jugoslavije (Mileševa. Monumentos artisticos en Yugoslavia). Belgrado.

Simić, P. (1987). Bogosluženja i freske XIII i XIV veka. (Oficios religiosos y frescos de los siglos XIII y XIV). In: Mileševa en la historia del pueblo serbio. Belgrado: Academia Serbia de Ciencias y Artes, p.103-109.

Tatić, M. (2007). Studije o Bogorodici. (Estudios sobre Virgen María) Belgrado.

Timotijević, M. (2001). Heroj pera kao putnik: tipološka geneza javnih nacionalnih spomenika i Valdecova skulptura Dosteja Obradovića. (El heroe de la pluma como viajero: Génesis tipológica de los monumentos nacionales públicos y escultura de Dositej Obradovi'de Vadlecş). Herencia III. p Belgrado. ISSN 1450-605

(2000). Suze i zvezde: O plaču Bogorodičinih čudotvornih ikona u baroku (Lágrimas y estrellas. Sobre el llanto de los iconos milagrosos de la Virgen María en el barroco). In: Milagros en la Cultura Eslava. Slovenska kapija no. 2. Novi Sad, p. 221-236.

Todić, B. (1992). Uvodna reč.(Introducción). In: Branislav Živković, Mileševa. Dibujo de los frescos. Arte medieval serbia 10. Belgrado, p.1-2.

Uspenski , L. (2000). Teologija ikone. (Teología del icono). Monasterio Hilandar.

\section{Catálogo de Figuras}

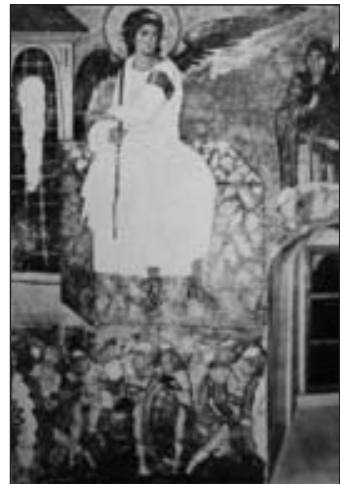

F1.

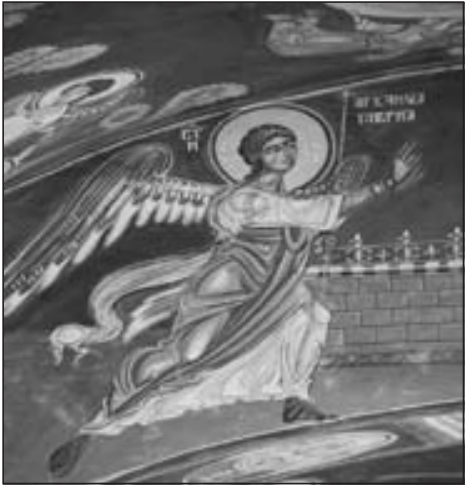

F2. 


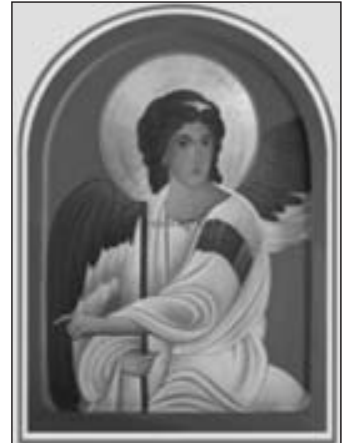

F3.

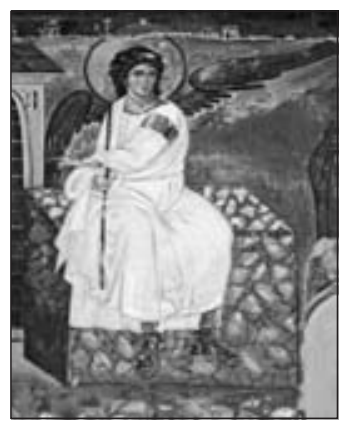

F5.

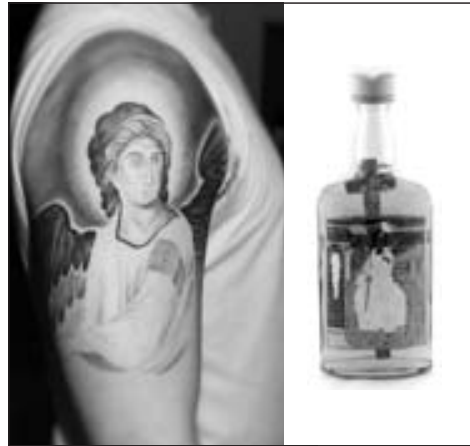

F4.

Figura 1. Las Miróforas en la sepultura de Cristo (Monasterio Mileševa, sudeste de Serbia). Fuente. www.privredaregiona.com/img/ed3d2c21991e3bef5e069713 af9fa6ca/Milesevski_BeliAndjeo_1.jpg

Figura 2. El Arcángel Gabriel de la Anunciación (Iglesia de la Transfiguración, Belgrado). Fuente. Elaboración propia.

Figura 3. El ícono Ángel Blanco. Fuente www.sveti-pantelejmon.com/Beli\%20 Andjeo\%202.gif

Figura 4. Un tatuaje del Ángel Blanco y una botella con la misma imagen. Fuente. www.tattooartists.org/Images/FullSize/000184000/Img184025_beli_andjeo.JPG Figura 5. El Ángel Blanco extraído desde la composición. Fuente. http://sanjaren ja56.blog.rs/gallery/2602/228_2_Freska-Beli-andjeo,-Manasti.jpg 
Summary: The murals in temples Christian Orthodox have always had the following objective: display the liturgical order and complete the religious experience of sacred time and space. Outside the temple and church, believers could maintain contact with these stories sanctified and holy, through the use of icons that have been an inseparable part of the Christian life always after the period of iconoclasm. In the communist era, the great successes of the art of Orthodox Christianity were observed outside the strict religious context. The change in attitude toward the visual arts influenced their marketing, largely neglected originating dogmas in which this art was based. An interesting fact is that the Serbian Orthodox Church significantly contributed to this process of marketing of orthodox art products.

This work will focus around a specific case -the case of the white angel-a world famous fresco, located in the Mileševa monastery (southwestern Serbia). In recent decades, this composition has undergone serious "reinterpretations" in which his main theme -the display of the empty tomb of Christ after his resurrection- has been marginalized for highlighting the white angel figure, through reproduction of only a section of the composition.

This case presents a testimony of several levels of current social and cultural processes in Serbia: bears witness of a long transitional process often supposed inventions and falsifications of national and religious traditions, testifies also on special forms called new religiosity, which is considered both a phenomenon both locally and globally, and last but not least, testifies to the secularization of the practices and orthodox faith.

Keywords: christian orthodox icon - marketing - resurrection - secularization - white angel.

Resumo: Os murais nos templos cristãos ortodoxos sempre tiveram o objetivo de visualizar o ordem litúrgico e completar a experiência religiosa do tempo e espaço sagrados. Fora do templo e ofícios religiosos, os crentes podiam manter o contato com estas histórias santificadas e seus santos, através do uso dos ícones que foram parte inseparável da vida cristã sempre depois do período da iconoclastia. Na época comunista, os grandes êxitos da arte do cristianismo ortodoxo se observavam fora do contexto religioso estrito. A mudança de atitude para as artes visuais influiu na sua comercialização que, em grande medida, descuidou os dogmas originários nos que este tipo de arte estava baseado. Um fato interessante é que a própria Igreja Ortodoxa Sérvia contribuiu de modo importante a este processo comercializando produtos de arte ortodoxa.

Este trabalho se centrará num caso específico -o caso do Anjo Branco- um fresco mundialmente famoso, do monastério Mileševa (sudoeste de Sérvia). Nas últimas décadas esta composição passou por sérias re-interpretações nas que seu tema principal-mostrar a tumba de Cristo vazia depois da Sua ressurreição- foi marginalizado por haver destacado a figura do anjo branco, através da reprodução só de uma parte da composição.

Este caso apresenta uma testemunha de vários níveis dos atuais processos sociais e culturais em Sérvia: dá testemunha de um longo processo transicional que frequentemente suponha invenções e falsificações das tradições nacionais e religiosas, testifica, também, sobre as formas especiais da chamada nova religiosidade, que é considerado tanto um fenômeno local como global, e, por último, mas não menos importante, testifica sobre a secularização das práticas e fé ortodoxas.

Palavras chave: anjo branco - comercialização - ícone (cristão) ortodoxo - ressurreição secularização. 